\title{
Voltage Behavior in the Switched Reluctance Generator Due to Different Speed Profiles Aimed at Use in Small Wind Turbines
}

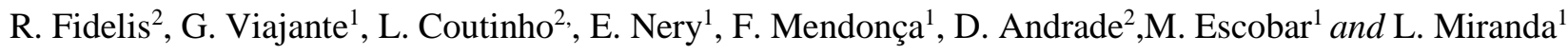 \\ ${ }^{1}$ Federal Institute of Education, Science and Technology Goiás, NUPSE \\ Campus of Itumbiara - Itumbiara, 75.524-010 Goiás (Brazil) \\ Phone/Fax number:+0055 64 21035600, e-mail: ghuntep@gmail.com and ricardotirone@gmail.com \\ ${ }^{2}$ Electric Drives Laboratory, Federal University of Uberlândia \\ Santa Mônica Campus, Uberlândia-MG, Brasil.
}

\begin{abstract}
This paper presents the implementation of an experimental platform for the study and drive the switched reluctance machine (SRM) as generator. Analyzing the behavior of the generated voltage at SRM at different speeds profiles. The driving was done through a data acquisition and processing system of high performance and low cost (DSP / FPGA). The results are shown and discussed.
\end{abstract}

\section{Key words}

Switched Reluctance Machine, Small wind Turbine, Generator.

\section{Introduction}

Renewable energy sources, such as the force of water, wind or the sun's energy and fossil resources, are among the fuels used for generating electricity. However, the rotating electric generators are responsible for almost all of the electricity produced. So that the importance of electrical machines in the global context of energy management and sustainability is unparalleled. It comes therefore evidence that the understanding of the characteristics and operational demands of electrical machines should be under continuous research, constant search for better flexibility rates, revenue and operating performance.

In this context the variable reluctance machine became an object of study for researchers around the world, especially with the advent of power electronics and the rapid development of Micro processing systems with high performance and low cost, contributing systematically to the switched reluctance machine becoming a strong candidate to be used as the motor/generator due to its intrinsic characteristics, which are: strength, absence of windings and permanent magnets in the rotor, a good power to weight ratio, high starting torque, ability to operate when lacking one of the phases in the case of multiphase machines, low construction cost and ease of design.
Thus, this work presents the implementation of an experimental platform to study and drive the SRM as a motor and generator and to study the influence of velocity on the generated voltage.

\section{Constructive Aspects of SRM}

Being composed primarily by a stator and a rotor with salient poles as shown in Figure 1, SRMs are machines simple to be designed and built, with the possibility of operation at variable or high speeds, presenting good heat resistance and eliminating the necessity of windings in the rotor thereby reducing its manufacturing costs.

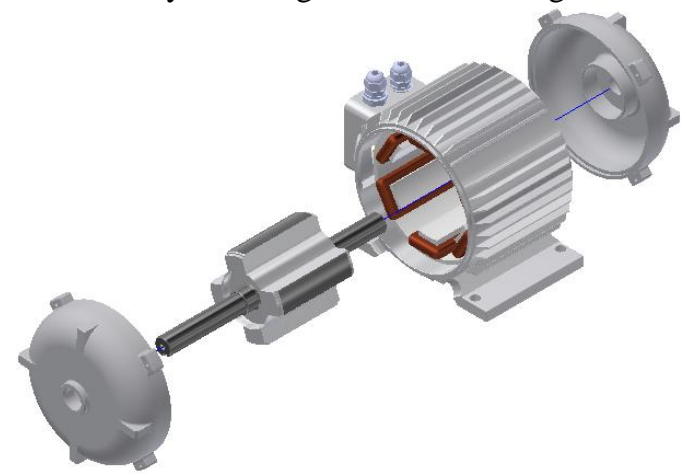

Fig. 1. General view of Switched Reluctance Machine.

The Switched Reluctance Machine operating as a generator acquires mechanical power from a primary source and convert into electrical energy. When one of the rotor poles is aligned with the stator pole excited, a stable equilibrium is created, causing a natural tendency of the rotor to align with the excited pole, which causes an increase in the inductance in this phase. The figure 2 shows the inductance profile obtained from SRM that depend mainly on the rotor shaft position and machine excitation current, the curve was obtained by finite element method and is presented in [1]. The curve represents a quarter turn, repeating the same behavior over the course of a ride, for all other stages the curve is shifted by 30 and 60 degrees. 


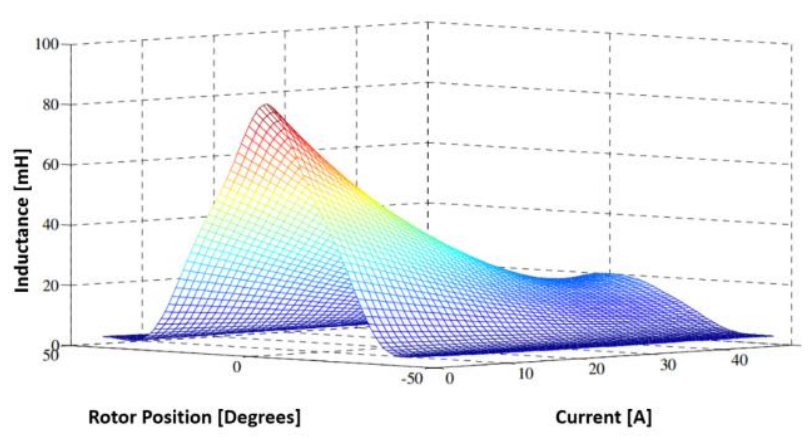

Fig. 2. Inductance profile for different values of current and position.

When an external force acts on the rotor in order to move it from its stable equilibrium position, comes a counterelectromotive force causing the voltage to rise and thus generating electricity. The counter-electromotive in SRM depends crucially on the current, speed of the machine and inductance variation of the position of the axis.

Since the excitement is done by applying direct current, the change in position will always be positive, so the sign of counter-electromotive force is determined by the inductance variation as a function of rotor position, thus defining the operation of SRM as a motor or generator.

\section{Experimental Platform}

The SRM drive process, along with its control can become somewhat complex and confusing, as you need to perform the interconnection of multiple devices and different circuits, which generally have distinct and isolated grounds. In order to facilitate the tests and trials, and leave the drive SRM in a didactic and simplified form, a workbench is designed to drive SRM, allowing it to be operated as a motor and generator. Figure 3 shows a simplified diagram of designed workbench.

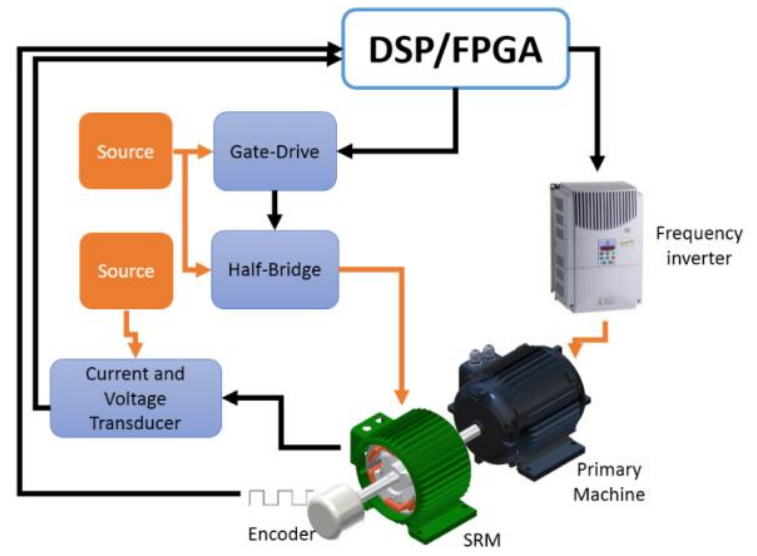

Fig. 3. Simplified diagram of the built workbench.

In operation the SRM needs a converter that provides excitement for it. The literature shows a variety of topologies of converters used for machine operation, however the most widely used due to operational characteristics is the Half-Bridge (HB) [1], [2], [4] e [7].
Figure 04 shows the circuit of this converter to drive an MRV $6 \times 4$ with a relay to determine the type of actuator to be held, motor or generator.

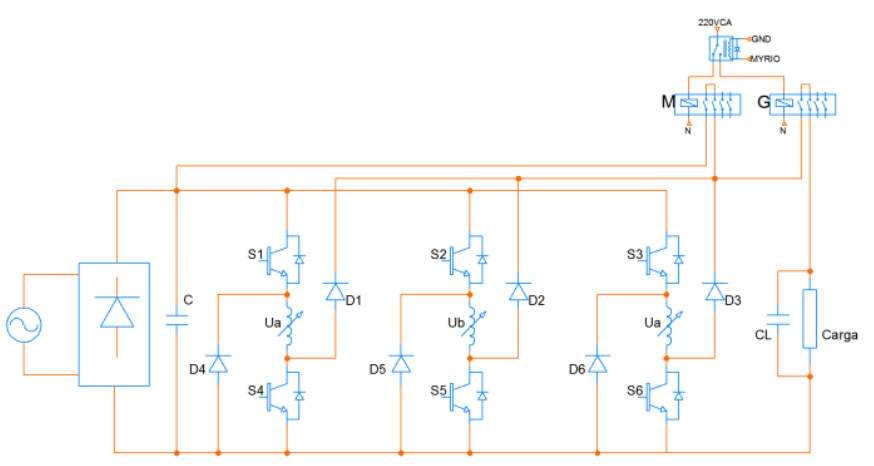

Fig. 4. Half-Bridge Converter (HB).

To perform the control and drive of the SRM it was used a DSP / FPGA device. Enabling the drive is done by the DSP processor, the FPGA device or by a parallel configuration between these two interfaces, significantly increasing the customization possibilities of the drive and control algorithms.

Figures 5 and 6 show the photo of the finished workbench, along with SRM, Primary Machine and the encoder.

As the primary machine a three-phase induction motor controlled by a frequency inverter was used, the SRM used was a $6 \times 4$ type with nominal power of $1 \mathrm{CV}$.

$$
\begin{array}{lc}
01 \text { - Load } & 06 \text { - DSP / FPGA } \\
02 \text { - Frequency inverter } & 07 \text { - Voltage Source } \\
03 \text { - Gate-Drive } & 08 \text { - Out SRV } \\
04 \text { - Voltage Source } & 09 \text { - Voltage and Current } \\
05 \text { - HB Converter } & \text { Transducer }
\end{array}
$$

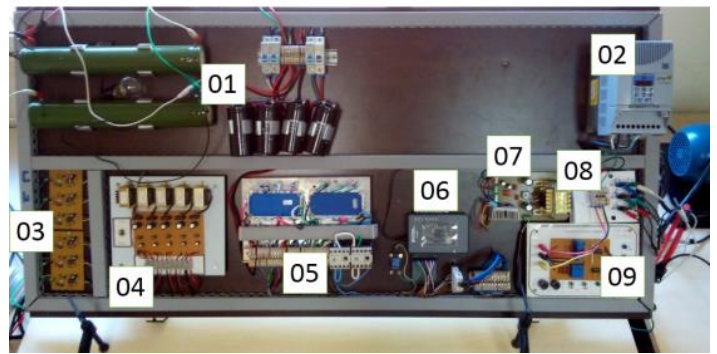

Fig. 5. Finished Workbench.

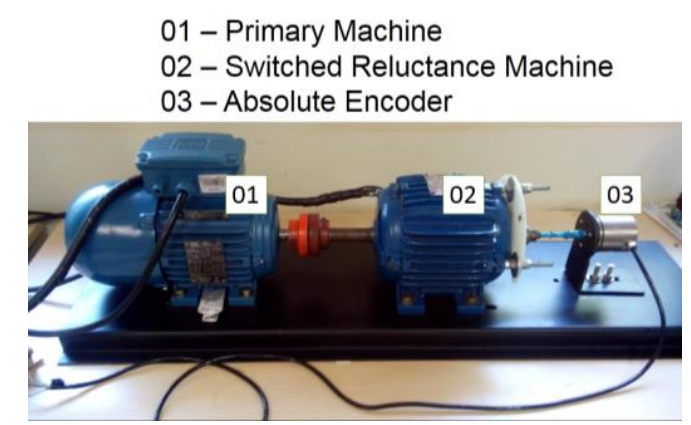

Fig. 6. Primary Machine, SRM and Encoder.

A supervisory interface was developed in Labview®, showing the main SRM's drive information, such as: 
- Show which phase is energized;

- View the encoder read values;

- Select the desired type of drive, motor or generator;

- Manually control the value of $\theta_{\text {off }}$ angle;

- Manually change the value of the spin of the primary machine;
- Move the encoder reference in relation to the phases of the machine;

Figure 7 shows oversight screen developed.

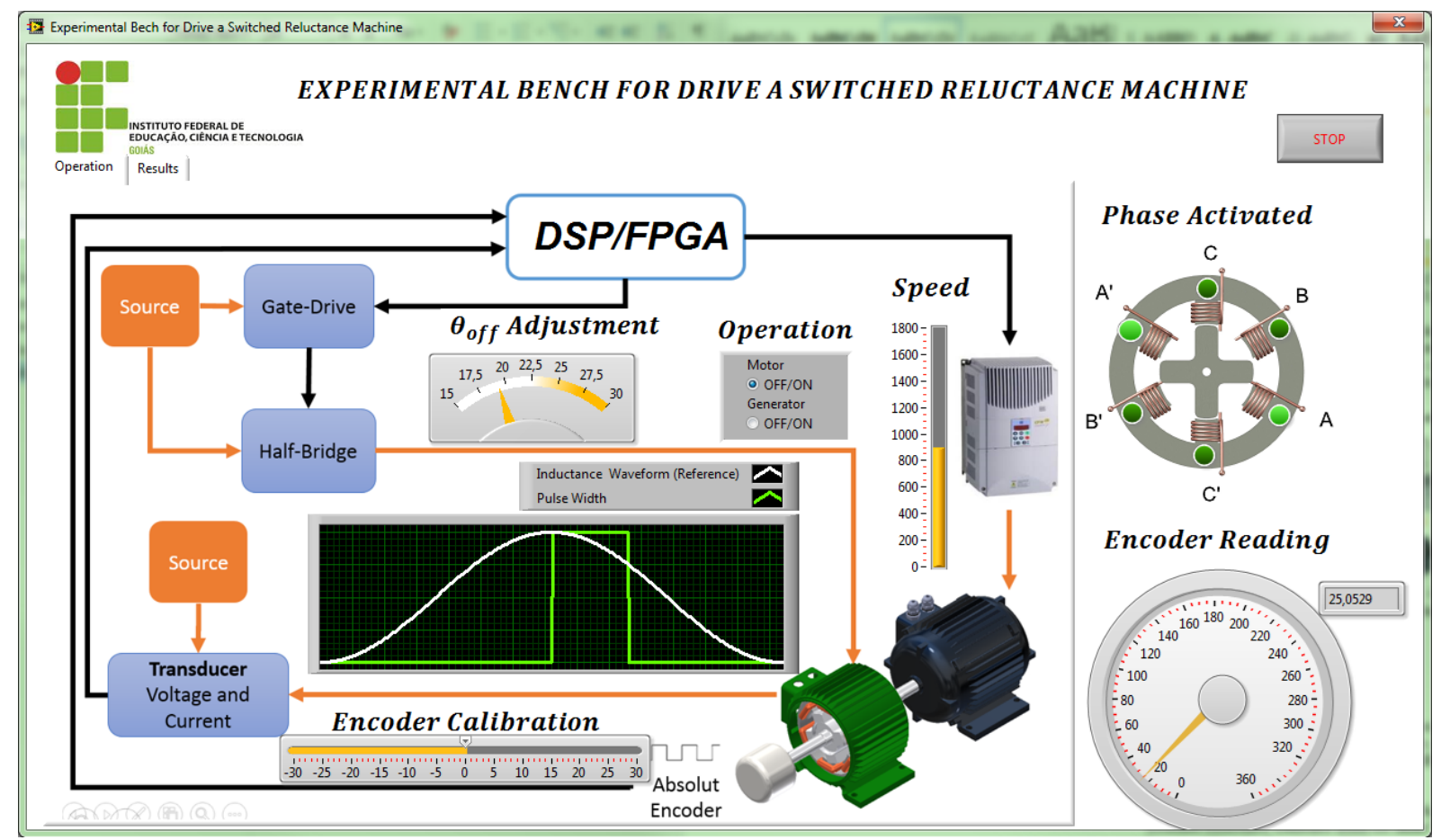

Fig. 7. Supervisory interface

\section{Experimental Results}

Some drives were made to check the operation of the workbench and investigate the behavior of the SRM from various points of operation and the influence of speed on the generated voltage.

During the activation of the SRM as a generator waveforms of voltage and current were collected, these waveforms are shown in Figures 8 and 9. Figure 10 shows the waveform of voltage at the load.

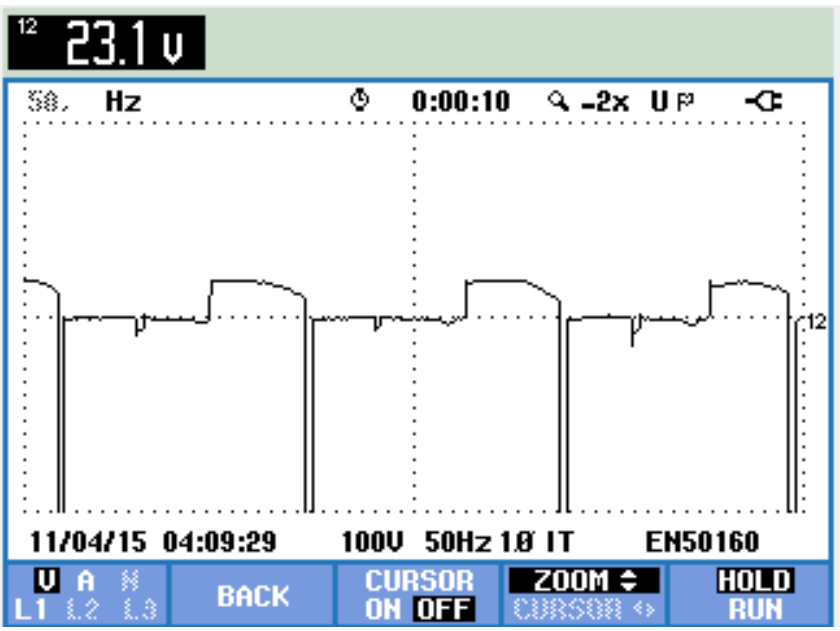

Fig. 8. Voltage Waveform (Generator)

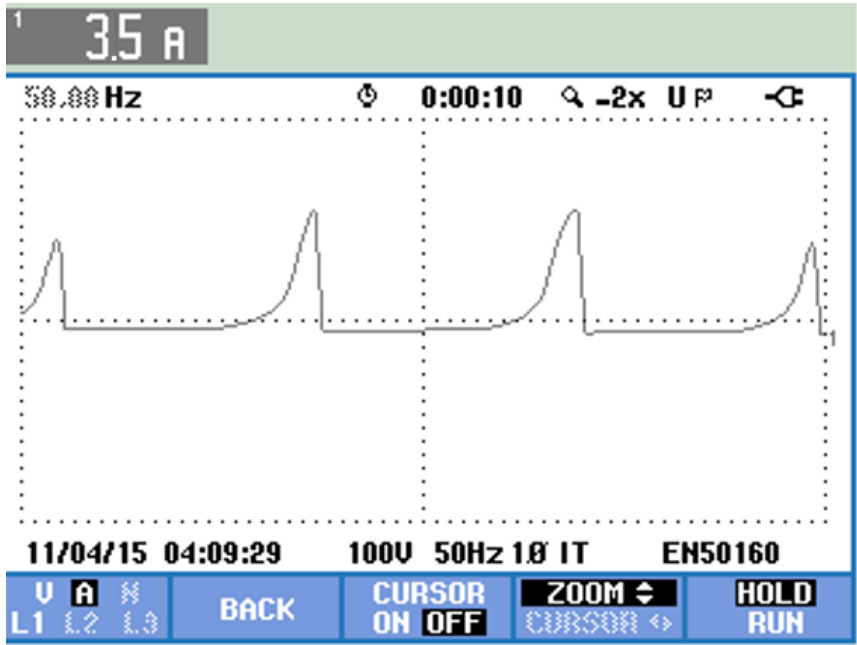

Fig. 9. Current Waveform (Generator).

During the drive, some tests were carried out to evaluate the behavior of the machine due to changing the drive speed and angles of excitement. Relevant characteristics of wind applications, where wind speeds are constantly changing with different speed profiles. 


\section{${ }^{12} 8.10$}

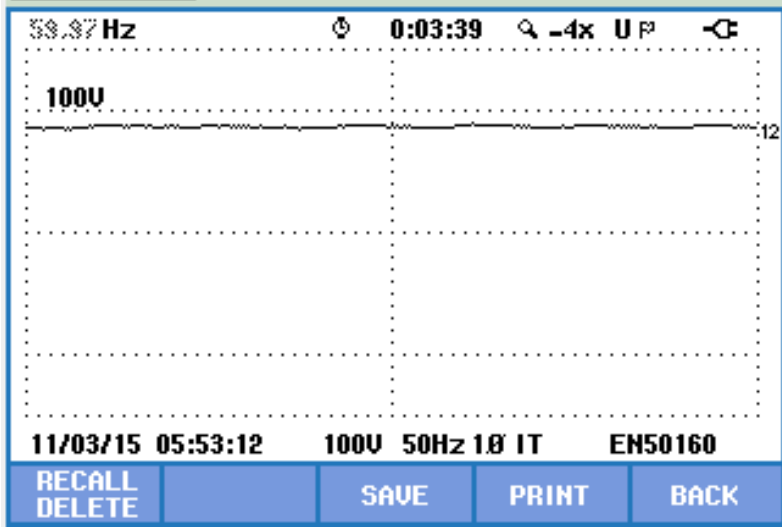

Fig. 10. Load Waveform.

The tests were performed in a $6 \times 4$ SRM $1,5 \mathrm{CV}$ operating with an open loop excitation $10 \mathrm{~V}$ and fixed magnetization angle of 30 (Maximum). The drive speed is limited within an intermediate range of velocity, which successfully represents the speeds applied in small wind turbines.

The results were collected using a digital oscilloscope "Tectronix TDS2012B" with a $10 \mathrm{KHz}$ sample rate, channel 1 being collected in a signal corresponding to the speed of the primary machine and channel 2 being the voltage delivered to the load. The results are shown in Figures from 11 to 15 .

Figure 11 displays the generated voltage due to a sinusoidal variation in speed, there was a variation of $15.99 \%$ in voltage for an increase of $93.9 \%$ in velocity.
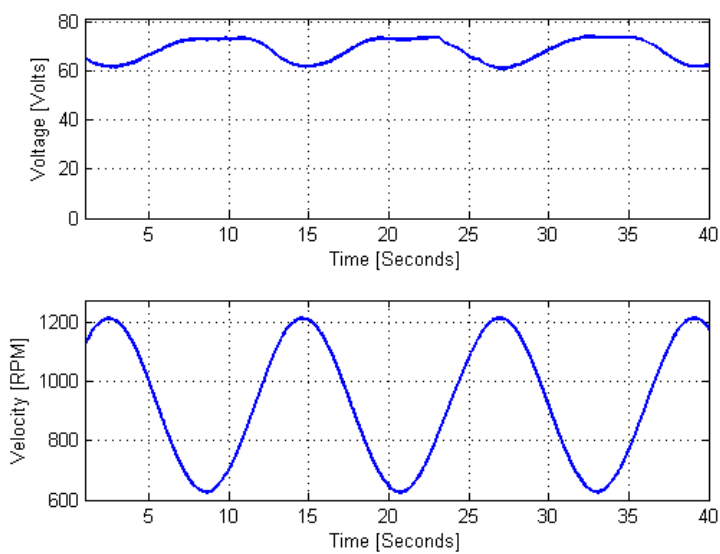

Fig. 11. Generated voltage as a function of a sinusoidal variation of drive speed.

Figure 12 shows the variation of the voltage with a step change in the speed profile, there was a variation of $16.22 \%$ on the generated voltage to an increase of $100.33 \%$ speed.

Figure 13 shows the generated voltage with a speed variation of a triangular profile, there was a variation of $16.96 \%$ on the generated voltage to an increase of $93.66 \%$ speed.
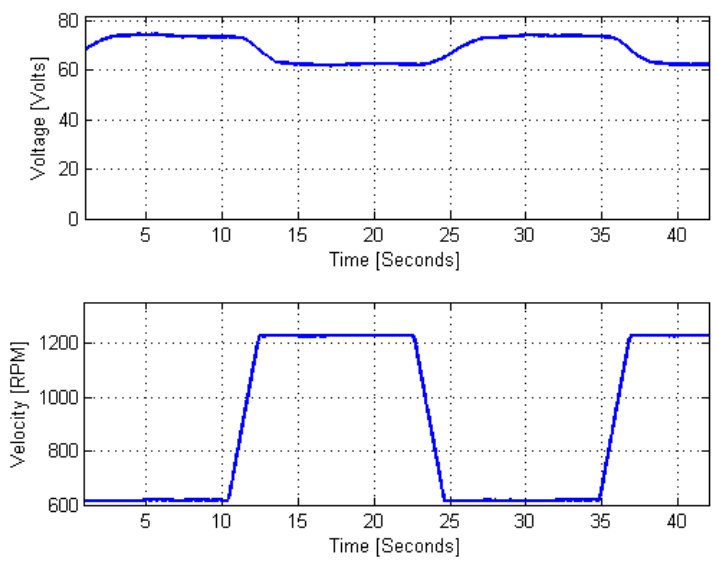

Fig. 12. Voltage generated as a function of a variation in the form of step drive speed.
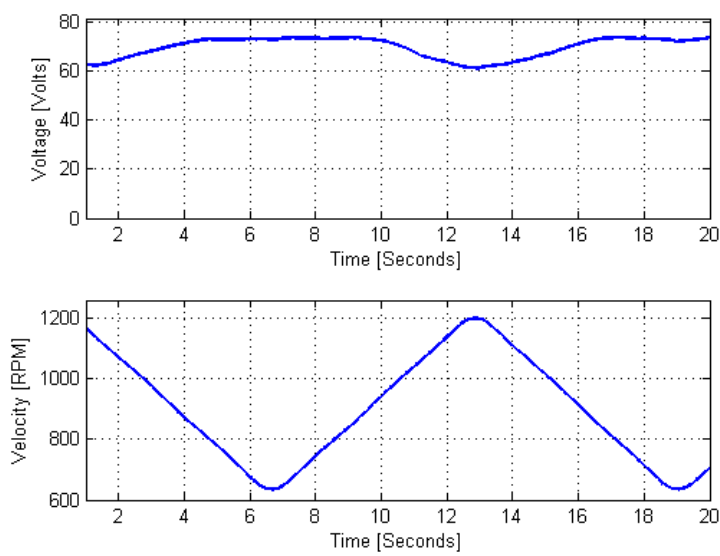

Fig. 13. Voltage generated as a function of a drive speed (Triangular profile)

Figure 14 shows the variation of the voltage with a sawtooth profile (gradient) in the speed profile, presenting a variation of $15.76 \%$ on the generated voltage to an increase of $88.84 \%$ of speed.
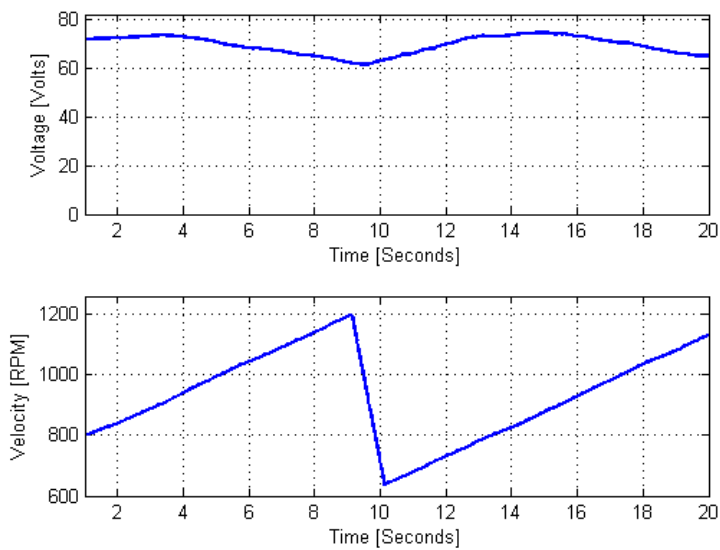

Fig. 14. Voltage generated as a function of a drive speed (gradient profile)

Table 01 presents a summary of the collected data, displaying the maximum and minimum values. 
Table 01 . Summary of the collected data

\begin{tabular}{|l|c|c|c|c|c|c|}
\hline \multirow{2}{*}{ Profile } & \multicolumn{3}{|c|}{ Velocity } & \multicolumn{3}{c|}{ Voltage } \\
\cline { 2 - 7 } & Min [RPM & Max [RPM & Variation [\%] & Min [N & Max [V] & Variation [\%] \\
\hline Sine & 624,00 & 1210,00 & 93,91 & 62,00 & 73,80 & 15,99 \\
\hline Degree & 614,00 & 1230,00 & 100,33 & 62,00 & 74,00 & 16,22 \\
\hline Triangle & 620,00 & 1200,70 & 93,66 & 61,20 & 73,70 & 16,96 \\
\hline Sawtooth & 636,00 & 1201,00 & 88,84 & 62,00 & 73,60 & 15,76 \\
\hline
\end{tabular}

An additional test was performed to show the influence of the magnetization angle, it was noticed a significant change in voltage generated with a change on the magnetization angle, allowing to control the generated voltage by controlling the firing angle. Figure 15 shows the curves obtained.
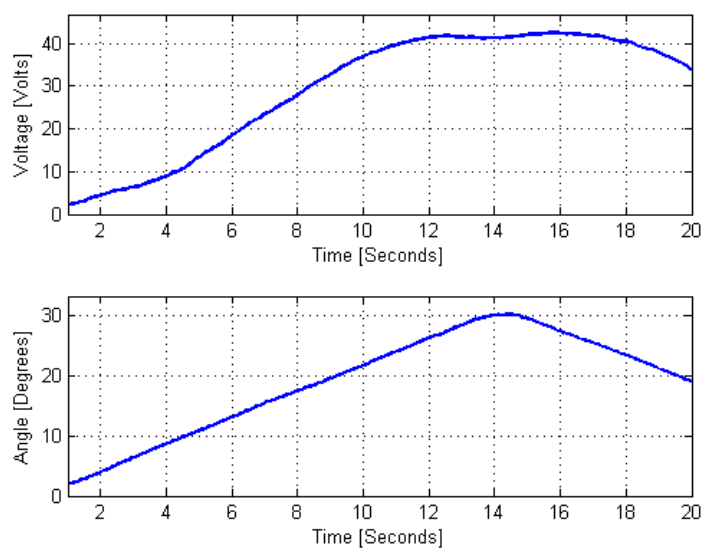

Fig. 15. Variation of the voltage generated due to the excitation angle

\section{Conclusion}

The drives have been finalized and the results were satisfactory. It was possible to observe the behavior of the voltage generated in relation to the variation of speed. It was observed that the effect of rotational speed operating ranges tested was not sharp, which indicates the ability to work with the SRM in a considerable range of speeds with little change in generated voltage. This feature is attractive for the use of SRG (Switched Reluctance Generator) in wind systems that allows to eliminate or alleviate the weight of the gearbox installed on top of the tower of the wind turbines. This, coupled with the drive simplicity and the general reduction in the cost of electronic components required for high-performance drive, makes the SRM a possible alternative for applications requiring variable speed.

\section{Acknowledgement}

The authors thank the Universidade Federal de Uberlândia, Escola SENAI de Itumbiara, Instituto Federal de Educação, Ciência e Tecnologia de Goiás, NUPSE and FAPEG for all the support.

\section{References}

[1] R. Fidelis, "Development of an Experimental Platform to Drive the Switched Reluctance Machine", ICREPQ, 2016, ISNN 2172-038.

[2] G. Viajante, "Gerador a Relutância Variável em Conexão com a Rede elétrica para Injeção de Potência Ativa", in Proc. UFU2013, CDU:621.3.

[3] A. Silveira, "Controlo $f$ the SEM operating as motor/generator", IEEE International Symposium on Industrial Eletronics, 2009, ISIE.

[4] D. Susitra, E. Jebaseli, A. Elisabeth, "Switched Reluctance Generator - Modeling Simulation, analysis and Control. A comprehensive Review", International Journal of Computer Application, 2010, Vol. $1 \mathrm{~N}^{\circ} 2$.

[5] F. Ribeiro, L. Cabral, A. Fleury. "A Switched Reluctance Generator Behavior Under Variable Speed an Variable Excitation", 2010.

[6] Z. Mohamed, T. Muthana, "Robust Controllers For Variable Reluctance Motors", Hindawi Publishing Corporation, 2005, Vols 195-214. DOi: 10.1155/MPE.2005.195.

[7] T. Miller, "Eletronic Control of Switching Reluctance Machine", Newness Power Engineering Series, 2001. 272 pp.

[8] A. Fleury, "Modelagem, Construção, Testes e Análise de Desempenho de um Gerador a Relutância Chaveado". UFU 2008, p258.

[9] A. Coelho, M. Aguiar, "Simulação, Projeto e Teste de um Gerador a Relutância Chaveado Trifásico 6x4". USP 2001 .

[10] F. Blaabjerg, "Power Eletronics in Wind Turbine System”, IPMEC-IEEE,2006. 